\title{
La criminalización de la desigualdad en la teoría de la justicia de David Hume
}

\section{The criminalization of inequity in David Hume's justice theory}

\begin{abstract}
Santiago Álvarez García *
Resumen

El presente trabajo tiene por objeto el estudio de una parte específica del pensamiento ético-político del filósofo escocés David Hume: sus descripciones acerca del origen de la justicia y el gobierno. Ambas son analizadas con la intención de esclarecer el tratamiento de la desigualdad que en ellas se ofrece. Nuestro objetivo es describir el particular proceso de criminalización de la desigualdad natural que comienza a producirse con la moralización de las leyes de la justicia tras la primera convención y se consolida tras la génesis del gobierno y el Estado.

El principal objetivo durante el ejercicio descriptivo de esta investigación será identificar el perfil y la función de los diversos protagonistas, así como la aparición del paternalismo moral y el dominio en la interactuación de los mismos. Por último, trataremos de ofrecer una solución verosímil a uno de los conflictos perennes en la literatura secundaria sobre la filosofía ético política humeana -la paradoja de la motivación-, reinterpretando el sentido de la estrategia adoptada por la figura del sensible knave.
\end{abstract}

Palabras clave

Justicia, desigualdad, paternalismo, dominio, sensible knave

\begin{abstract}
This work aims to study a specific part of the ethical and political thought of Scottish philosopher David Hume: his descriptions of the origin of justice and government. Both are analyzed in an attempt to clarify the treatment of inequality that it is offered by them. We describe how the particular process of criminalization of natural inequality begins to occur with the moralization of laws of justice after the first convention and how it is consolidated after the genesis of government.

During this particular descriptive process our main goal will be to identify the profile and role of the various players, and the emergence of moral paternalism and dominance in the interaction thereof. Finally, try to offer a credible solution to one of the perennial conflicts in the secondary literature on Hume's ethic philosophy - the paradox of motivation-, reinterpreting the meaning of the strategy adopted by the figure of the sensible knave.
\end{abstract}

\section{Keywords}

Justice, inequality, paternalism, dominance, sensible knave.

Forma sugerida de citar: ÁLVAREZ, García Santiago (2013). "La criminalización de la desigualdad en la teoría de la justicia de David Hume” en: Universitas, XI (18), enero-junio, pp. 79-99. Quito: Editorial Abya-Yala.

\footnotetext{
* Ld., doctorando en Filosofía. Universidad de Sevilla. e-mail: gargantua36@hotmail.com. Artículo de Santiago García: Recepción 29 de octubre de 2012 y Aceptación 2 de mayo de 2013.
} 


\section{Introducción ¿A qué problema da la justicia solución?}

La justicia, según Hume, es el artificio humano para la resolución de un doble conflicto evolutivo. De un lado, el conflicto psicológico generado por una pasión caníbal, la interested affection o avidity, cuya sed de posesiones insaciable, perpetua y universal, amenaza con la destrucción de cualquier tipo de sociedad. Del otro, el conflicto pre-social de la inestabilidad de las posesiones transferibles, o posesiones externas. Ambos conflictos se generan y retroalimentan de manera progresiva hasta volverse críticos, en un escenario -la extensión en número de los pequeños reductos de familiares y amigos-, inevitable para el ser humano.

El individuo humeano, - un amasijo informe atravesado por desordenados recuerdos, creencias y pasiones-, incapaz de contrarrestar sus vicisitudes y emergencias, encuentra en la satisfacción del apetito sexual la semilla que dará origen a la estructura cooperativa de la que tendrá más tarde que germinar a la fuerza la sociedad. Convertido en amante, en padre al cuidado altruista de sus hijos, y en amigo, en virtud de su capacidad empática y la extraordinaria influencia que la cercanía ejerce sobre sus pasiones, su genética no volverá jamás a ese primer estadio solitario. Urgido a mantener la estabilidad de su familia, se verá obligado a imponer normas de estabilidad para las posesiones de sus hijos que eviten incómodos conflictos. Aprenderá de su posición jerárquica en la familia los beneficios de tales normas. También lo hará su progenie, educada en la cooperación humana y sus beneficios, de los cuales, la creencia en las bondades del respeto a las posesiones de los demás será, sin duda, el más significativo de todos.

La experiencia familiar domará, pues, el self interest de tal modo que este no aparecerá ya como un impulso netamente egoísta, toda vez que ha visto incorporada a la monotonía de su objetivo de satisfacción individual la panoplia de intereses de aquellos a los que ama y cuida (Hume, 1978: 491-492).

La avidez de posesiones -estigmatizada por Hume como principal causa psicológica del problema al que hace frente la justicia-, no se perfila, a priori, y en este primer estadio evolutivo, como una pasión autodestructiva dentro de esos pequeños grupos formados por familias y amigos (Hume, 1978: 491-492). Sin ir más lejos, la tendencia natural en esos círculos es la ausencia misma del 
sentido de propiedad (Hume, 1826: 253). Su rasgo devastador y autodestructivo, su condición de problema, aparecerá cuando la sociedad natural sufra los efectos de un inevitable crecimiento demográfico que transformará, de un lado, la avidez natural del nuevo individuo en una pasión negativa, y del otro, su entorno en un escenario de escasez peligrosamente inestable (Hume, 1978: 487-488).

Hume da por supuesto en el Treatise que este doble proceso afecta por igual a todos los individuos, sin embargo, dicha interpretación es a todas luces incoherente partiendo de la misma antropología humeana. Describiremos el proceso natural de crecimiento demográfico humeano de manera analítica a fin de vislumbrar qué produce el problema y a quiénes afecta. En el origen de la sociedad, el concurso de las pasiones y de la propia cercanía conforma los círculos de amistad entre las diferentes familias. Tenemos pues un primer estadio donde las posesiones no sufren ninguna inseguridad ni contingencia. En ese primer estadio, los bienes externos no suponen un problema para los agentes: no son escasos; satisfacen a todos; y además, su reparto, en el caso de que no hubiera una abundancia razonable, está garantizado por los lazos afectivos a pesar del concurso de la avidez. En este sentido, este primer núcleo de familias unidas por la amistad que denominaremos $(\alpha)$ tiene una ventaja significativa respecto de los que vendrán a incorporarse más tarde a la estructura: no solo puede elegir primero y fortalecer los lazos de unión en virtud de la ausencia de escasez, sino que puede añadir el factor tiempo a la posesión y dotarla (más adelante) de legitimidad.

Partiendo de esta situación inicial, es fácil comprobar cómo un grupo $(\beta)$ de familias unidas por la amistad, incorporado en un momento posterior al territorio (un territorio que se ha visto reducido por el ejercicio satisfactorio de la avidez de $(\alpha)$ ), tendrá una desventaja respecto de $(\alpha)$ a la hora de ejercer sobre el territorio su deseo de posesión. Su campo de elección se verá reducido y el peligro de que sus lazos afectivos sean menores aumentará debido a que estos dependen de la ausencia de escasez en una primera instancia.

El resto de grupos humanos posteriormente incorporados mantendrán, pues, una desventaja progresiva respecto de sus predecesores en el mismo sentido. La suma y el equilibrio tendrán un límite claro: el momento en el que las posesiones disponibles no satisfagan las necesidades de los nuevos miembros 
incorporados, y su deseo solo se vea satisfecho con la sustracción de propiedades de los elementos de los grupos anteriores. En ese momento, la pre-sociedad natural entrará en el territorio de la inestabilidad, y los miembros sentirán, de facto, la inseguridad de sus posesiones, otrora pieza clave de su estabilidad.

Podemos imaginar entonces, a medida que el tiempo transcurre y que se desgajan elementos del grupo $(\beta)$ y nuevos elementos se incorporan, la aparición de un tercer grupo $(\gamma)$. Este último grupo encierra lo que bajo mi interpretación es la clave del desajuste a raíz del cual se origina lo que Hume denomina "las circunstancias de la justicia". Este tercer grupo está en una desventaja respecto del primer y segundo grupo, no relativa, sino casi absoluta. La adquisición progresiva de los bienes por parte de los diferentes grupos, ha convertido el ejercicio de estabilidad del grupo $(\gamma)$ en una imposibilidad, o mejor dicho, ha convertido en una imposibilidad la adquisición de posesiones por parte de este último grupo sin incurrir en la desposesión de recursos de los grupos $(\alpha)$ y $(\beta)$, haciendo imposible el establecimiento del nexo de la amistad entre las familias $(\gamma)$.

Es esa situación la que define el colapso de esos grupos que hasta ahora convivían pacíficamente en virtud de sus constituciones naturales, es decir, fruto de la naturaleza humana y su empatía. Son, pues, los miembros de los grupos $(\alpha)$ y $(\beta)$, y en ningún caso los del $(\gamma)$, los que tienen conciencia del problema, los que empiezan a comprender que la estabilidad social reside en la garantía de la estabilidad de las posesiones que ya se poseían. Partiendo de este escenario, caben dos visiones del conflicto que se produce en Hume justo antes de la aparición de la convención que dará origen a las leyes de la justicia. Una primera versión a la que llamaremos versión individualista, y una segunda versión a la que llamaremos versión grupal.

La versión individualista: tras la incorporación de $(\gamma)$ al esquema protosocial de Hume, todos los grupos, en función de la progresión de las escaramuzas, pierden su estabilidad, es decir, las escaramuzas se generalizan, y tanto $(\alpha)$ como $(\beta)$ pierden sus ventajas relativas respecto de los miembros de $(\gamma)$ y respecto de ellos mismos. En esta versión, todos tendrían necesidad de actuar de forma justa, ya que, todos poseerían posesiones suficientes, fruto de un sin fin de incursiones, escaramuzas y robos, que habrían acabado con la seguridad y la estabilidad de las posesiones, pero que, paradójicamente, habrían equili- 
brado las posesiones actuales de modo que la motivación para reconocer derechos en los demás estaría asegurada. Si bien esta versión salva el escollo de la exclusión, vuelve, sin embargo, a Hume incoherente: asegurar la motivación de todos los individuos significa que la inestabilidad de las posesiones tiende a equilibrarse en contextos de inseguridad y que la justicia no es necesaria.

La versión grupal: con la incorporación de $(\gamma)$ al esquema pre-social $h u$ meano, los grupos $(\alpha)$ y $(\beta)$ no pierden estabilidad, es decir, sus componentes no ven mermadas su confianza en los miembros de sus grupos respectivos, sino que identifican la amenaza proveniente de los miembros de $(\gamma)$. Ambos grupos comprenden que su interés solo se puede ver satisfecho estableciendo actuaciones de consenso progresivo sobre el respeto por las posesiones; y lo hacen, porque han aprendido de la cooperación, tanto en la familia como con los miembros de su grupo, que eso es rentable a largo plazo. Su único interés en hacerlo debe responder a que les interesa mantener sus posesiones y necesitan de la garantía de su seguridad.

En esta lectura, habría un grupo de individuos que, a pesar de formar un grupo (unidos por el momento de su aparición en el escenario pre-social), no serían sino individuos, o mejor dicho, familias ciertamente aisladas y desfavorecidas cuyas únicas posesiones serían las obtenidas en el pillaje. Los miembros del grupo $(\gamma)$ poco interés pueden tener en mantener el status quo con el que se encuentran, ya que, precisamente, la desventaja que cargan debido al momento temporal de su llegada les penaliza con la miseria y con la incapacidad de poder hacer sentir a los demás su resentimiento.

En el modelo grupal, observamos cómo las circunstancias donde la justicia hace su primera aparición como solución efectiva solo constatan que la única forma en la que la sociedad puede volverse estable en su totalidad es: o bien la exclusión de la misma de los que no gozan de estabilidad interna, y la cooperación progresiva por ensayo error de todos los que de alguna forma pueden sentirse dentro del espectro, bien porque sus propiedades se lo permitan, bien porque su creencia les haga sentirse beneficiarios de ese modelo; o bien con la exigencia de un contrato que garantice la redistribución del territorio de modo que los individuos más desfavorecidos puedan mantener, de manera racional, la creencia de que acatar las normas de restricción de la justicia les favorece. 
Sin embargo, esta última opción es descartada por Hume a través de su rechazo de la promesa como origen del pacto social y su crítica a la capacidad de la razón frente a las pasiones en el famoso slave reason pasagge. La promesa, para Hume, es ininteligible en estado de naturaleza; su ejercicio por parte de la voluntad es sencillamente inexistente, $y$, en caso de darse, incapaz de constituir una obligación. El rechazo de la promesa como fundamento de la sociedad implica en última instancia el reconocimiento de la incapacidad del hombre para restringir su tendencia natural de manera autónoma y voluntaria y equilibrar así la desigualdad derivada de la lotería natural; su impotencia a la hora de salvar las circunstancias e imponerles una regulación artificial para el beneficio de todos sin excepción; la imposibilidad de generar un contexto moral imparcial y universal más allá del interés personal o la inclinación natural.

Serán entonces las emociones, los instintos y las creencias, las que motivarán a determinados individuos a adoptar artificios que dotarán al progreso natural de las relaciones de fuerza entre los agentes de nuevas formas que harán las relaciones humanas más estables. Será entonces la opción de la exclusión y el dominio -viable sin el concurso de la promesa-, dentro de la versión grupal, la que cobre forma en la descripción humeana de la convención, habilitando a su vez una doble motivación factible dentro del propio esquema de Hume que dará solución a la paradoja de la motivación.

\section{El origen de la justicia II: la sociedad justa}

La convención y la estabilización posterior de las reglas de la justicia en Hume sigue una progresión que podemos dividir en tres estadios a los que podemos asociar tres motivaciones distintas: un primer momento en el que el resentimiento individual de un agente y su deseo de castigar a su enemigo hacen surgir un nuevo self-interest reorientado y artificial que adopta como estrategia la cooperación a través del reconocimiento de la propiedad de aquellos que, a través de la sympathy, considera que están en su misma situación -y que no supone una "restricción" de la avidez toda vez que sendos grupos beneficiados en la lotería natural no han experimentado en la misma esa metamorfosis que la volvía negativa; un segundo estadio en el que la imitación hace acto de presen- 
cia y constituye la moralización progresiva de los actos de justicia en función de las consecuencias positivas que se derivan de los mismos; y por último, el desarrollo de una creencia-norma inoculada en la educación que sirve como motivación artificial para la justicia para aquellos en los que el interés individual no se identifique con la misma.

\section{El motivo no-moral para la justicia}

Ha sido un locus tradicional dentro de las reflexiones en torno a la justicia la afirmación de la inexistencia de un motivo no moral para los actos justos dentro de la teoría de la justicia de Hume (Gauthier, 1992; Darwall, 1993). Sin embargo, la afirmación definitiva de la inexistencia de un motivo no-moral en Hume parte de dos errores fundamentales: El primero, la confusión del motivo "artificial" con el motivo "moral" y su contraposición con el motivo "natural". El segundo, la no distinción entre el principio del primer motivo virtuoso (el primer motivo virtuoso que dota de mérito a una acción, nunca puede ser una consideración sobre la virtud de la acción, sino que debe ser algún otro principio o motivo natural [no moral]), y la máxima indubitable (ninguna acción puede ser virtuosa, o moralmente buena, a menos que haya algún motivo en la naturaleza humana que la produzca, distinto del sentido de su moralidad) (Garret, 2007).

Garret defiende que el único rechazo del que podemos estar seguros es el del motivo no artificial para la justicia, y en ningún caso el de una motivación no moral. Sin embargo, incluso Garret yerra en su interpretación al atribuir la motivación originaria al enlightened self interest. La consistencia del mismo como motivo no moral (natural) desaparece cuando se enfrenta al examen de los rasgos psicológicos que mueven a la acción: la esperanza en el placer y la aversión del dolor (Hume, 1978: 414). Somos incapaces de encontrar un placer o un interés individual en llevar a cabo los actos de justicia más allá del sentido propio de su equidad, o de los límites propios de la artificialidad. Sin embargo, dos cuestiones salvan de la paradoja la narración de Hume: la primera es el hecho de que, partiendo de una elaboración más profunda de las causas de la justicia, como la que propusimos con la versión grupal, podemos comprender 
que en realidad las acciones de justicia en el origen de la sociedad no son una "restricción", sino más bien un "reconocimiento", y que este "reconocimiento", como veremos más adelante, no supone un ejercicio contrario a los instintos naturales del individuo.

El reconocimiento es la consecuencia de la modificación del self interest, provocada por un deseo que busca su satisfacción y su placer en el individuo a raíz de las circunstancias descritas en las que la justicia hace su aparición, y que Hume identifica con el deseo de castigo para nuestros enemigos (Hume, 1978: 439). Si los actos de justicia, en su origen, son el ejercicio de la satisfacción de ese deseo, tendremos resuelto el problema de la motivación no moral para la justicia y la satisfacción del primer motivo virtuoso, ya que se trataría de una inclinación natural reconocible por todos aquellos que, teniendo posesiones, formarán parte de la justicia.

Si revisamos todo lo descrito hasta ahora, la solución al problema de la motivación no moral se nos muestra clara. El primer agente que articula la estrategia cooperativa lo hace en función de dos parámetros: En primer lugar, desde el punto de vista natural, lo que lo mueve es su deseo de castigar a aquellos enemigos que a través de escarceos ponen en riesgos sus posesiones. Partiendo de la cuarta condición de la justicia, es obvio que puede contrarrestar y hacer sentir su resentimiento de manera individual. Sin embargo, la experiencia de la multiplicidad de los mismos, y su propia experiencia asociativa, le hacen pensar que sus enemigos pueden asociarse fácilmente (Hume, 1978: 503).

Es entonces cuando el self interest se reorienta y el individuo descubre que debe seguir las directrices de la sympathy respetando las posesiones de aquellos que como él, están en la misma situación de incertidumbre y comparten un interés mutuo en regular de esa forma su comportamiento (SBN 490). En este sentido, la transformación adoptada por el self interest del agente no entra en contradicción con sus deseos, ni con sus inclinaciones. Los individuos de los grupos $(\alpha)$ y $(\beta)$ no tienen que restringir ninguna avidez; en ellos, ésta no se perfilaba como un rasgo autodestructivo. Solo tienen que reconocer el status quo de los demás y convertir sus posesiones en propiedad para estar seguros de que todos orientarán su resentimiento de forma conjunta contra aquellos que los amenazan. Los deseos de estos individuos y su experiencia proto-social previa elaborarán de manera artificial un nuevo motivo; un motivo que aun no es mo- 
ral, que tampoco es ya natural, pero que satisface las exigencias del principio del primer motivo virtuoso: el enlightened self interest. La semilla para la eclosión de una clase social dominante ha sido sembrada. El grupo $(\gamma)$, convertido en enemigo merced a la lotería natural será, inevitablemente, el objeto de ese dominio.

\section{La convención: exclusión y paternalismo. La no-paradoja de la motivación}

De las cuatro circunstancias que dan origen a la justicia (el egoísmo, la generosidad limitada, la escasez (Hume, 1826: 3-12), y la igualdad en la fuerza -medida por la capacidad de hacer sentir a los demás nuestro resentimiento(Hume, 1826: 261-2), es sin duda esta última la que justifica en mayor medida la versión grupal de la que nos hicimos eco arriba y la inevitabilidad de la exclusión que la misma contiene. No puede haber justicia entre agentes con una desigualdad notable. El famoso pasaje de la Enquiry muestra que aquellos más vulnerables (todos aquellos incapaces de hacer sentir su resentimiento a los demás) quedan fuera del alcance de las condiciones de justicia, y son abandonados al ejercicio paternalista por parte de los demás, fruto del deber moral hacia la humanidad que dicta tratar a las criaturas vulnerables decentemente. Sin embargo, no está claro que el deber moral hacia la humanidad, proporcione una protección adecuada a los débiles. Si aquellos que son extremadamente vulnerables son, sin embargo, seres racionales, capaces de sentir resentimiento y completamente capaces de juicio autónomo acerca de cómo vivir (como podemos considerar al grupo $(\gamma)$ ), entonces, la teoría de Hume les reserva el peor tipo de protección (Ridge, 2010).

Coexiste, pues, con la desigualdad, la obligación moral por parte de los individuos capaces de hacer sentir ese resentimiento, de controlar y dirigir las vidas de todos aquellos que, por algún u otro motivo, han quedado fuera de la convención de la justicia. Existe, pues, una obligación paternalista respecto de los colectivos que han quedado fuera de la justicia y una justificación, a través de la benevolencia, para cualquier medida que se tome bajo el supuesto de una mejora de sus condiciones. Ninguno de ellos participa, pues, de manera activa 
de los beneficios de la justicia; ninguno de ellos forma parte de la convención que la constituye; más bien, son arrastrados por ella, y en el caso de los individuos del grupo gamma, sencillamente el objetivo de la misma.

Cualquier miembro de $(\gamma)$ se encuentra, cuando los comportamientos de justicia empiezan a aparecer, ante una paradoja de aislamiento. Su estrategia dominante es siempre la misma. Hagan lo que hagan los demás, él debe seguir o bien con las incursiones, o bien con la exigencia de un pacto o contrato de redistribución de las posesiones, pues no tiene nada que perder. Luego, el problema de la motivación para la justicia (manido en la bibliografía secundaria en torno a Hume) deja de ser un problema en sentido estricto toda vez que diferenciamos a individuos distintos con naturalezas evolucionadas de manera diferente en función de las circunstancias, ya que las clases beneficiadas sí están motivadas, y las que no, han quedado sencillamente fuera de la justicia.

\section{La convención. La formación del interés común y las clases sociales}

La expresión mutua del interés común será la pieza angular que hará funcionar la convención (Hume, 1978: 490). Sin embargo, y a pesar de que, como se ha expuesto hasta ahora, ciertos individuos comparten intereses comunes, nada indica que estos individuos, en el estado pre-social en el que se encuentran, sean capaces de expresarse mutuamente sus intenciones cooperativas. Matthew Kramer alertó de esta incoherencia dentro del discurso humeano sobre el origen de la justicia (Kramer, 1989).

Según Kramer, para que la expresión del interés común -pieza fundamental del puzzle de la justicia- se diera, era necesaria la existencia de un lenguaje común entre los individuos llamados a ser los protagonistas de la convención; sin embargo, para la existencia de un lenguaje común entre esos individuos era necesaria, paradójicamente, la existencia de una sociedad extensa y bien constituida. Necesitamos postular, pues, junto con Allan (Allan, 1992), la posibilidad de una comunicación prelingüística y progresiva de las intenciones para entender y hacer plausible cómo la convención se impone al mismo tiempo que el propio lenguaje (Hume, 1978: 490). 
El respeto de un individuo "a" de las posesiones de un individuo "b", es interpretado por este segundo individuo como un gesto positivo para su propio interés, y tras una evaluación egoísta similar a la realizada por "a", deduce los beneficios comunes de mantener una actitud recíproca. Es ahí, en la respuesta del segundo individuo, donde la "expresión mutua" del interés común se hace patente. No hay, pues, en el origen de la convención, actos justos que tienen como horizonte la totalidad del esquema de la justicia. De haber sido así, en nada se habría diferenciado del esquema holístico hutchensoniano. El interés común se genera progresivamente entre la clase de los poseedores. La justicia no es aceptada por todos, ni tampoco es comunicado el interés común a todos. Se establece de manera progresiva y solo entre aquellos cuyos intereses en juego se ven satisfechos con dicha estrategia.

Si antes de la aparición de la sociedad justa la alternativa natural no contenía en sí misma ninguna dosis de violencia, una vez constituida ésta, la topografía natural adoptará unos perfiles más agresivos y peligrosos (Hume, 1978: 497). La aparición de la sociedad obliga a aquellos que no formaron parte de la convención debido a su desigualdad: o bien a la soledad más salvaje y destructiva, o bien a la sumisión a las reglas establecidas que, a pesar de no ofrecerles su protección, les concede el beneplácito de la buena voluntad de aquellos que sí poseen la fuerza suficiente para formar parte de la convención. En este sentido, todos aquellos que por su debilidad natural, o por su falta de posesiones, etcétera, no vieron satisfechos sus intereses con las reglas de propiedad, o simplemente no pudieron contrarrestar las iniquidades que padecieron en el origen, se ven obligados por la nueva fuerza social a someter sus voluntades a las de aquellos que en virtud de su humanidad guiarán ahora sus destinos.

\section{La moralización de la justicia}

Establecida la sociedad; ejercido el dominio sobre aquellos más desfavorecidos; su progresivo desarrollo eliminará del horizonte humano la amenaza de la injusticia. Es entonces cuando su soporte antropológico, aquella motivación proporcionada por el enlightened self interest-suma de deseo de castigo y artificioso reconocimiento- se desvanece. Llega el turno de la sympathy; el 
momento fundamental de la moralización de la justicia y su establecimiento definitivo como una virtud artificial (Hume, 1978: 499).

Los vínculos establecidos entre los agentes "a's" y "b's" del epígrafe anterior son reconocidos por sus protagonistas de utilidad "pública". La experiencia de sus beneficiosos efectos se vuelve creencia, y ésta, pieza fundamental para que a través de la sympathy compartamos el sufrimiento de aquellos que padecen injusticias y el placer de aquellos que la respetan; una conexión mediada por una perspectiva no privada ni interesada que dota de virtud el respeto por la propiedad, las transacciones de bienes y el cumplimiento de las promesas constituyéndolas en una obligación moral. Una sympathy, sin embargo, selectiva, que sólo conecta los sentimientos de dolor y placer de aquellos susceptibles de sufrir injusticias.

Si la virtud de una acción dependía, en la ética humeana, de su aprobación desde un punto de vista general, es decir, imparcial, éste no se da, al menos en toda su extensión, en la aprobación de la justicia. Si nuestras ideas de moralidad no cultivadas y naturales eran incapaces de resolver la parcialidad de nuestras afecciones, esta imparcialidad no se ve resuelta con la aparición de la justicia y la sociedad. La parcialidad de la afección y de las ideas morales naturales persiste en la sociedad, toda vez que el resentimiento provocado por las injusticias padecidas por aquellos agentes racionales incapaces de hacer sentir a los demás su rencor, no puede ser trasmitido o detectado por la sympathy.

Los agentes que originan la valoración moral de la justicia son individuos educados social y familiarmente para defender el status quo al que pertenecen; su forma de interpretar la generalidad o la universalidad está mediada en exceso por su creencia (no tanto por su razón) y sugestionada e ideologizada en un primer estadio por la familia y en un segundo estadio -constituida la sociedad política-, por la propaganda y el artificio de los políticos. Su imparcialidad, se encuentra supeditada a las condiciones que como grupo dominante han impuesto a los demás; lo público de la utilidad de sus reglas se reduce al estrecho cerco de aquellos que partiendo de posesiones han prosperado en un clima de paz y de libres y consentidas transacciones. 


\section{La creación del gobierno y la estrategia del sensible knave}

El desarrollo de las reglas de justicia y su consiguiente moralización suponían, al menos teóricamente, el fin de cualquier elemento distorsionador de la paz entre los hombres. Sin embargo, los beneficios de la justicia escondían dos problemas endémicos en la sociedad que reclamaban la necesidad imperiosa de la creación de un artificio más poderoso que el precedente. El primero de ellos consistirá, según Hume, en la irrefrenable tendencia humana a preferir lo cercano a lo remoto -inclinación que nos hace olvidar por momentos qué acciones satisfacen con mayor eficacia nuestro "verdadero" interés; el segundo tendrá que ver con la imposibilidad de coordinar cualquier acción colectiva con eficacia.

Respecto del primer problema, el desaprendizaje social de la justicia, Hume parece querer decirnos que la estabilidad de la justicia por sí misma es imposible. Su propio desarrollo, su capacidad para la paz entre los individuos acaba volviéndose caníbal, y como un Cronos enfurecido devora a su progenie transformando, el otrora prudente juicio de los individuos que dieron origen a la justicia, en una suerte de ligereza y cegueras dominadas por lo cercano y trivial frente a los intereses a largo plazo. Estos mismos individuos, alejada toda probabilidad de injusticia, se ven inclinados a desarrollar nuevas estrategias que los alejan de la senda de las leyes de la propiedad y que, en vista de las nuevas dificultades que provocan, los conducen hacia la creación de un nuevo artificio, esta vez mucho más poderoso: el gobierno.

Pero, ¿Es esto posible? ¿El ejercicio de la justicia no ha operado ningún cambio en los agentes? ¿Pueden los individuos en sus decisiones, tras la experiencia individual de los beneficios de la justicia, seguir siendo guiados por una imaginación y una creencia huérfanas de nuevos datos? ¿Pueden las nuevas generaciones de individuos sustraerse a la fuerza de la educación y la creencia en las virtudes de la justicia? ¿Se ha producido realmente un des-aprendizaje de la justicia en el desarrollo de la misma, o son otras las causas de esta conflictiva tendencia por lo contiguo que colapsa a la sociedad justa?

Los individuos que entraron en el intercambio recíproco de reconocimientos que configuró las normas de la justicia y la estabilizaron convirtiéndola en una virtud artificial capaz de una obligación moral pasaron por dos momentos 
educacionales que no pueden ser obviados: en primer lugar, la experiencia social que, en la familia, transformaba los instintos del hombre y los relajaba en favor de una solución social a sus conflictos. El sujeto que daba pie a la convención de la justicia no era ya un individuo "natural", sino proto-social, es decir, su capacidad para evaluar qué beneficiaba sus intereses hacía tiempo que no estaba dominada por ningún parámetro excesivamente egoísta. Una vez instituida la justicia, una segunda "oleada pedagógica" continuaba la transformación del individuo. Si bien el interés natural cedía su fuerza al paso del crecimiento social, la obligación moral, hija de las consecuencias socialmente positivas de los actos justos y nuestra aprobación de los mismos, se hacía parte de nuestra conciencia e imponía la observación de las leyes de la justicia.

Tales modificaciones en la naturaleza del individuo hacen difícil y poco verosímil la idea de que los miembros del primer grupo desanden pasos tan firmes. Sólo si el hombre, en el discurrir del tiempo, puede olvidar sus intereses en la justicia y retraerse a su más primitiva tendencia egoísta tendría sentido la afirmación que los postulase como protagonistas de esta primera causa que incline la balanza del artificio hacia el gobierno. Sin embargo, la estructura con la que Hume describió el origen de la creencia en el libro primero del Treatise, y su impacto sobre la acción del hombre, demuestran que el individuo se nutre, de manera irremediable, de reglas generales y prejuicios de los que le es imposible separarse, al punto que sus pasiones no podrán entrar en conflicto con sus creencias (Phillips, 2005), y que éstas, por otra parte, pueden arraigarse incluso sin haber sido experimentadas de forma directa por los individuos, ni constatada su certeza (Hume, 1978: 84), así como sin la ayuda de una extensión larga en el tiempo que las vuelva costumbre.

Esto último implica que si bien los primeros beneficiarios de la justicia la ponían en funcionamiento, al principio, movidos por la mezcla del instinto y el enlightened interest, y más tarde en virtud de la creencia fundada en la experiencia de sus beneficios; las generaciones posteriores tienen su juicio supeditado al relato de las virtudes de la justicia que sus predecesores han elaborado, y por lo tanto, sus intereses concretos están determinados por dichas narraciones, así como su acción subordinada a la creencia misma. Las creencias son la base de los comportamientos que se sobreentienden de sentido común, en este sentido, los organigramas de decisión de los individuos no responden, una 
vez han sido educados o han experimentado impresiones asociadas a principios de inducción, a los intereses individuales naturales, sino que, lejos de eso, sus intereses se modulan para siempre y lo individual se mezcla con lo colectivo, entendiendo lo colectivo como esa especie de interés social que se gesta a medida que la creencia en la justicia se hace más sólida. El interés, en este estadio desarrollado de la sociedad, no se constituye tras un razonamiento individual que tiene en cuenta de forma objetiva las condiciones materiales y circunstanciales que rodean al individuo, habida cuenta de la desaparición de las causas amenazantes para la sociedad en la injusticia. No podemos, pues, afirmar que los individuos que han participado de la justicia de forma estable se separen de la misma según se desvanece el horizonte de posibilidad de la injusticia debido a que sus intereses ya no están dominados por ciertas creencias de las que no han tenido experiencia directa.

El perfil de la naturaleza social de aquellos que ponen en riesgo "de nuevo" a la sociedad debe estar huérfano de la experiencia o la educación en los beneficios de la justicia, así como de unas creencias que adapten sus pasiones y modifiquen sus intereses en favor de la observación de las leyes de la propiedad. Sólo cabe la posibilidad de que sean los agentes excluidos de la justicia no dominados por completo los que supongan esta nueva amenaza para la sociedad.

\section{El origen del gobierno y la criminalización de la desigualdad}

La creación del gobierno se plantea, pues, como el único remedio posible al colapso de la sociedad que se adivina en semejante coctel. El objetivo del mismo será, bajo las premisas impuestas por Hume, transformar nuestras circunstancias y convertir la observación de la ley en nuestro interés más cercano y su violación en el más remoto (Hume, 1978: 537). Si en el caso de la justicia el interés individual de los poseedores frente a la amenaza de la inestabilidad de las posesiones los convocaba a cooperar, esta vez no será distinto salvo por un detalle: lo que hay que instituir comporta un grado de violencia y coerción difíciles de asumir por todos, incluidos aquellos que no gozan de una mala posición social. 
El perfil humano que describe la solución gubernamental es el de aquel cuyo interés privado se identifica parte a parte con la observación escrupulosa de la justicia. La naturaleza y su azar habían colocado ya en una posición inmejorable a ciertos individuos, -beneficiados por la lotería natural con mayor fuerza y propiedades-, para servir como respuesta a tales interrogantes. Lo que en el estado de naturaleza no era más que una desigualdad propiciada por el momento temporal en el que los individuos accedían a dar rienda suelta a su avidez, sumada a la fuerza con la que la naturaleza había dotado a cada uno para hacer notar su resentimiento, y que, tras la primera convención había visto transformado su carácter arbitrario en una categoría moral que identificaba como virtuosos los actos de reconocimiento derivados de la estrategia de aquellos agraciados con la fuerza o la época, y como viciosos aquellos comportamientos urgidos por una naturaleza similar pero instalados en las circunstancias de los débiles, se convierte ahora en un poder legítimo y cuasi omnímodo para usar la violencia más coercitiva contra aquellos que no observen las leyes que se impusieron lentamente tras la primera convención.

No hay espacio para el examen de las cualidades "humanas" de los que detentarán el poder. La justicia y sus normas, cuyo criterio último fue la fuerza (para el reconocimiento entre los iguales y la exclusión de los débiles) sirve de criterio ahora para la composición y la estructura del poder, y convierte, en una metamorfosis cuasi mágica, la capacidad natural para la violencia en una capacidad moral llena de legitimidad capaz de reconducir las voluntades más dispares.

Los castigos y la violencia se convertirán en las medidas coercitivas que reorientaran a la fuerza la tendencia de aquellos que por determinadas circunstancias en nada salían ganando con la justicia. La persecución de las injusticias, conocidas ya las distintas fases de dominio sobre aquellos que solo siguen las mismas tendencias naturales que sus vecinos colocados en una mejor posición, supone, pues, la criminalización de una actitud natural legítima. Aquellos desposeídos de la posibilidad de las posesiones "dignas", que luego fueron descartados del ejercicio y los beneficios de la justicia, comprueban ahora el verdadero significado de su debilidad.

El gobernante puede nombrar ministros, formar un ejército, constituir un Estado y obligarlos definitivamente a asumir su rol inferior dentro del esquema 
artificial: el "es" de los beneficiados se ha transformado en un "deber ser". Las "leyes naturales" que surgieron del artificio creado por los poseedores se convertirán precisamente en eso, en naturaleza, habida cuenta de que la disidencia será eliminada o bien con la violencia física del propio Estado, o bien con la violencia ideológica de la educación dirigida por los políticos. No ha habido, en la descripción de Hume, opción para los débiles en ningún momento. Tampoco la habrá ya para todas esas generaciones por venir. Todas se encontrarán presas en la claustrofóbica metáfora del barco; atrapadas por una serie de convenciones y equilibrios de los que serán incapaces de zafarse (Hume, 1978: 520).

\section{Un puzzle llamado "sensible knave": las posturas de Gauthier y Baier.}

El sensible knave es uno de esos puzzles teóricos que se resiste a ser integrado en una interpretación holística de los trabajos de Hume. La mayoría de las interpretaciones, obsesionadas con la paradoja de la motivación (Garret, 2007), caen en el error de confundirlo con la figura del free rider. Quizá dos de las aproximaciones más elaboradas, y que más se acercan a nuestra propuesta, sean las de David Gauthier (Gauthier, 1992) y Annette Baier (Baier, 1992).

Para Gauthier, el sensible knave representa una puesta en cuestionamiento de la afirmación humeana de que el individuo gana más con la observación estricta de las reglas de justicia que por la ocasional y cuidadosamente calculada (y no detectada) brecha de las mismas. La conclusión de Gauthier confirma una paradoja interesante: solo el sensible knave conserva su integridad como individuo en su totalidad, ya que, demostrado que la sociedad humana carece de fundación moral, observar la justicia supone una concesión de nuestro propio interés. Para Gauthier, como para Marcia Baron, no existe ninguna motivación natural o artificial salvo la educación y el autoengaño para observar las leyes de la justicia.

Desde la lectura de Baier, el "engañado" o "self-deluded non-knave" es susceptible de mantener su integridad intacta. Ante la pregunta de dónde reside el verdadero interés Baier se decanta por el rechazo de la duplicidad que supone la estrategia del sensible knave en favor de la estrategia del non-knaves que rechaza los premios materiales de la injusticia por ser juguetes de poco 
valor y chucherías (worthles toys and gewgaws). El principal error de Gauthier, según Baier, es ignorar la escala de reconfiguraciones que el individuo opera sobre sí mismo a medida que se van sucediendo los distintos artificios. Si bien la estrategia del sensible knave puede ser efectiva en determinados escenarios, -como por ejemplo durante el proceso de la primera convención donde el ensayo y el error darían poco a poco forma a las reglas de la justicia-, sería del todo suicida una vez instituido el gobierno. En el primer artificio los hombres no veían peligrar sus vidas, estaban acostumbrados a un trueque rudimentario, y las posibilidades de éxito de un "ladrón sensato" podrían suponer una motivación verosímil. Sin embargo, cuando el segundo artificio se pone en funcionamiento, la amenaza de la violencia gubernamental, o la propia perdida de un valor intransferible como la reputación, convertían la posibilidad de adoptar la estrategia del sensible knave en una posibilidad ridícula.

Bajo nuestro punto de vista, ambas lecturas aciertan y yerran casi por partes iguales. Gauthier está en lo cierto cuando desvela la imposibilidad de obviar que una estrategia como la del sensible knave pone en cuestionamiento la propia teoría de la motivación de la justicia. Y de hecho, está en lo cierto cuando afirma que un individuo que comprobara la viabilidad de dicha estrategia tendría que estar equivocado o auto-engañado para observar las leyes de la justicia. Lo que, sin embargo, se le escapa a Gauthier es la posibilidad, contemplada en esta investigación, de que dicha estrategia no sea sino el resultado final de la adaptación de las distintas estrategias adoptadas por los excluidos una vez que la sociedad política ha puesto sobre ellos todo el foco de su violenta y vigilante atención, y no, un recurso homogéneo a la mano de todos los individuos que componen la sociedad.

Yerra también Gauthier cuando cree que la única motivación para la observación de la justicia es el autoengaño o la modificación personal a través de la educación. Ya vimos que un sector de la población tiene severos motivos naturales para seguir la justicia no solo tras el primer artificio, sino tras el segundo como acabamos de ver arriba. Sí es cierto que la educación convierte a las generaciones siguientes en seguidoras de la justicia, pero ya hemos comprobado la existencia de una naturaleza impermeable, al menos en el primer estadio de la convención, a esos cantos de sirena que inoculaban las bondades de la justicia; son precisamente aquellos que no están convencidos desde un principio 
de su efectividad los que dan lugar a la creación del gobierno. Solo cuando el gobierno ha impuesto su fuerza y su ideología a través del artificio educacional de los políticos podemos estar seguros de que todos son "engañados" en la virtudes de las normas de la propiedad. El sensible knave precisamente surge en esa dialéctica.

Baier con buen criterio había afirmado que tras la sociedad política seguir las leyes de la justicia era sin duda la mejor estrategia. Olvidaba Baier que esa es siempre la mejor estrategia para aquellos que no están bajo las condiciones de la necesidad o la pobreza. El sensible knave es la única respuesta que los "definitivamente dominados" por la aparición del gobierno tienen de mantener su dignidad.

\section{El sentido de la estrategia del sensible knave}

Sometido por el poder estatal y manipulado por los diferentes artificios de los políticos desde su educación dentro de la sociedad política, el individuo $(\gamma)$ solo puede desarrollar una estrategia viable para mantener viva la inclinación natural y legítima de su avidez dentro de la sociedad política (una suerte de enlightened self interest del desfavorecido): aprovechar los espacios en los que la fuerza del gobierno no sea efectiva, y en los que su acción no suponga una amenaza susceptible de ser castigada. Si destacamos de la descripción de la estrategia del sensible knave, no el hecho de no ser descubiertos, sino el hecho, consciente por parte del individuo, de que su acción no perjudicará a la sociedad en su conjunto, observamos cómo el sensible knave, integrado forzosamente en el devenir socio político y eliminado como amenaza directa, encuentra el hueco que habilita la posibilidad de realizar aquello que su naturaleza le dice que es su interés y que en nada se diferencia de aquella tendencia originaria que dio lugar a la gestación de la justicia por parte de los individuos $(\alpha)$ y $(\beta)$. El débil ha encontrado, pues, la forma de reclamar su particular "derecho a la propiedad"; su manera de aprovechar los vacíos de la justicia dentro de la sociedad política y desarrollar su libertad. El progresivo éxito de su estrategia puede otorgarle voz en el futuro y capacidad para "hacer sentir su resentimiento". Su ejercicio puede encontrar imitadores. La repetición de su estrategia no supondrá el fin 
definitivo de la sociedad, sino algo más extraordinario aun, y políticamente más relevante: el principio del cambio social y revolucionario.

La estrategia del sensible knave supone pues el centro neurálgico de la dialéctica social humeana. En ella reside el origen de cualquier cambio no violento de ese frágil fundamento que sustenta al poder avanzado el tiempo: la opinión. El hombre en Hume construye siempre su propia historia, pero no como quiere. Levanta sus instituciones nuevas sobre los defectos de las anteriores. Es ese el doble destino reservado al sensible knave dentro del esquema humeano: de un lado, el mantenimiento de su dignidad natural a través del ejercicio de su interés legítimo frente al ejercicio impositivo de los demás; del otro, y toda vez que su ejercicio sea imitado por aquellos que en su misma situación soportan el ejercicio coercitivo del resto de la sociedad, su transformación en el germen de un cambio social progresivo protagonizado por aquellos que reclamarán frente al Estado la justicia que se les debe.

\section{Bibliografía}

ALLAN, James

1992 “Justice, Language and Hume: A Reply to Matthew Kramer". Hume Studies. 18.1.

BAIER, Annette

1992 "Artificial Virtues and the Equally Sensible Knaves: A Response to Gauthier". Hume Studies. 18.2

BARRY, Brian

1995 Teorías de la justicia. Barcelona. Gedisa.

DARWALL, Stephen

1993 "Motive and Obligation in Hume's Ethics". Noûs. 27.4.

GARRET, Don

2007 "The First Motive to Justice: Hume's Circle argument Squared”. Hume Studies. Vol. 33. $\mathrm{N}^{\mathrm{o}} 2$.

GAUTHIER, David

1992 "Artificial Virtue and the Sensible Knave". Hume Studies. 18.2.

HOPE, Simon

2010 "The Circumstances of Justice". Hume Studies. 36.2. 
HUME, David

1978 A Treatise of Human Nature. ed. L.A. Selby.Bigge; $2^{\mathrm{a}}$ ed., rev. por P.H. Nidditch. Oxford. Clarendon Press.

1826 The Philosophical Works of David Hume. ed. T.H. Green y T.H. Grose. Edimburgo: Black and Tait. 4 Vols.

KRAMER, Matthew

1989 "The Deferral of Nature in Hume's Theory of Justice". The Canadian Journal of Law and Jurisprudence 2. $\mathrm{N}^{\mathrm{o}} 2$.

PHILLIPS, David

2005 "Hume on Practical Reason: Normativity and Psychology in Treatise 2.3.3" Hume Studies. 31.2.

RIDGE, Michael

2010 "David Hume, Paternalist". Hume Studies. 36.2.

Recepción 29 de octubre de 2012 y Aceptación 2 de mayo de 2013. 